J. Lake Sci.(湖泊科学), 2008, 20(2): 184-190

http://www.jlakes.org. E-mail: jlakes@niglas.ac.cn

(C)2008 by Journal of Lake Sciences

\title{
基于水体透明度反演的太湖水生植被遥感信息提取*
}

\author{
张寿选 ${ }^{1,2}$, 段洪涛 ${ }^{1}$, 谷孝鸿 ${ }^{1}$ \\ (1: 中国科学院南京地理与湖泊研究所湖泊与环境国家重点实验室，南京 210008) \\ (2: 中国科学院研究生院, 北京 100049)
}

摘 要: 在使用多光谱遥感图像提取太湖水生植被分布时，由于水体中悬浮物和藻类等物质的影响, 容易产生“异物同谱”现 象, 大面积水体被误分为沉水植被. 本文首先通过 TM 图像反演太湖水体的透明度，基于 RVI 和 NDVI 植被指数，分别建立两 类决策树, 即透明度辅助的分类决策树和无透明度参与的分类决策树, 将太湖分为水体、以浮叶植被为主导的水生植被和以 沉水植被为主导的水生植被等三种类型. 透明度辅助下的 NDVI 分类决策树方法, 较好地消除分类过程中的 “异物同谱” 现 象, 是进行太湖水生植被分类的一种最好方法选择，把这种方法应用于 2002 年 7 月 15 日的 Landsat ETM 卫星遥感影像, 结果 表明太湖中以沉水植被为主导的水生植被约 $407.6 \mathrm{~km}^{2}$, 以浮叶植被为主导的水生植被约 $82.2 \mathrm{~km}^{2}$.

关键词: 水生植被; 遥感; 决策树; 透明度; 太湖

\section{Remote sensing information extraction of hydrophytes based on the retrieval of water transparency in Lake Taihu, China}

\author{
ZHANG Shouxuan ${ }^{1,2}$, DUAN Hongtao ${ }^{1} \&$ GU Xiaohong ${ }^{1}$ \\ (1: State Key Laboratory of Lake Science and Environment, Nanjing Institute of Geography and Limnology, Chinese Academy of \\ Sciences, Nanjing 210008, P.R.China) \\ (2: Graduate School of Chinese Academy of Sciences, Beijing 100049, P.P.China)
}

\begin{abstract}
There exists a phenomenon of different objects with a similar spectrum in the multispectral satellite images in Taihu Lake, which is caused by an influence of suspended matter and algae. So, it is easy to classify the water into submerged vegetations area by mistake. In this report, we firstly retrieved water transparency from Landsat TM image acquired on 15 July 2002 . And then, the following two types of decision trees were developed on the basis of the two vegetation index of RVI and NDVI: (a) a transparency-assisted decision tree, (b) a non-transparency-assisted decision tree. Finally, the lake was divided into the following three types: (a) the water area, (b) the submerged vegetation-dominated hydrophytes area, (c) the floating vegetation-dominated hydrophytes area. The classification approach with transparency-assisted decision tree is a good choice to have a classification of hydrophytes in Taihu Lake. We applied this approach into the Landsat TM image acquired on 15 July 2002. The classification results showed that the submerged vegetation-dominated hydrophytes and the floating vegetation-dominated hydrophytes covered an area of about $407.6 \mathrm{~km}^{2}$ and $82.2 \mathrm{~km}^{2}$, respectively.
\end{abstract}

Keywords: Aquatic vegetation; remote sensing; decision tree; transparency; Lake Taihu

太湖平均水深约 $2 \mathrm{~m}$, 是一个典型的大型浅水湖泊, 富营养化严重, 水华频繁暴发, 悬浮物浓度高, 平均透明度很低，真光层深度较浅，限制了大型水生植被特别是沉水植被的生长 ${ }^{[1-2]}$. 准确获取水生植被 及其生物量的空间分布信息，可以帮助我们正确诊断水生生态系统的健康状况，为湖泊食草性鱼类的放

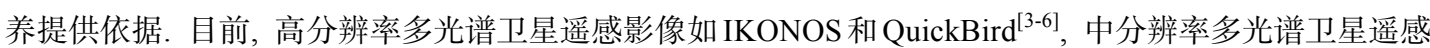
影像如 Landsat $\mathrm{ETM}^{[7-9]}$ 等都已被成功地用于湖泊水生植被监测. 有研究表明，水生植被分布与水体透明

* 江苏省自然科学基金(BK2007261)、国家自然科学基金(40671138)和国家科技支撑计划(2007BAC26B01)联合资助. 2007-09-05 收稿; 2007-11-06 收修改稿. 张寿选, 男, 1980 年生, 硕士研究生; E-mail: zhangshouxuan8@163.com. 
度关系密切, Stewart 和 Freedman ${ }^{[10]}$ 对比研究了不同透明度的两个湖泊, 发现水体透明度、营养状态、酸 碱度和水深等对水生植被空间分布以及生物量有重要影响, 其中水体透明度起主导作用; Squires 等 ${ }^{[11]}$ 认 为水生植被的生物量随水体透明度的增加而增加. 由于水生植被的分布受水深的影响, 详细的水深数据 能够帮助提高沉水植被的制图精度 ${ }^{[12]}$. 本文试图以水体透 明度作为辅助数据, 通过 Landsat TM 卫星遥感影像, 较高 精度地获取太湖不同类型水生植被的空间分布信息.

\section{1 数据}

选取 2002 年 07 月 15 日的 Landsat ETM 卫星影像及 其具有相同空间分辨率的 1-5 和 7 波段, 使用 1:50000 地 形图进行几何精校正, 均方根误差为 0.39 个像元. 同日对 太湖进行了实地观测, 共设 15 个采样点(图 1). 13-15 日天 气状况良好, 能见度很高, 风速均在 2 级以下, 15 日的实地 观测可以视为卫星影像的准同步观测. 野外观测时, 使用 手持 GPS 接收机记录采样点的地理坐标, 使用塞氏盘 (Secchi disk)在船的背阳面测量水体的透明度.

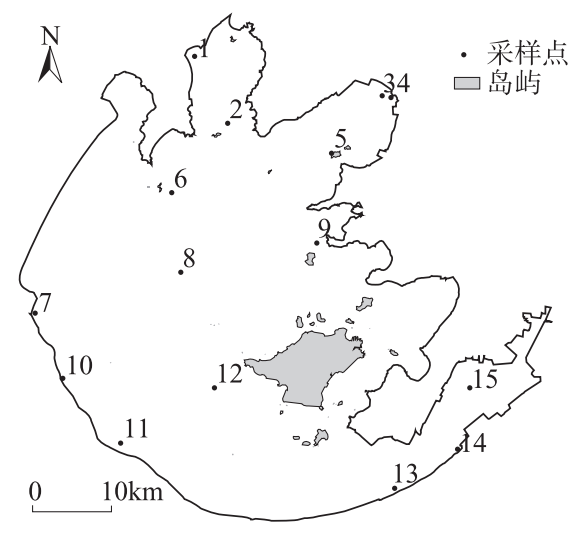

图 1 样点分布

Fig.1 Distribution of the sample points

\section{2 方法}

把整个太湖分为光学深水区和光学浅水区两个部分 ${ }^{[13]}$; 在光学深水区，离水辐亮度(或 DN 值)不受底 质的影响, 在光学浅水区, 依水深和透明度的不同, 底质对离水辐亮度(或 DN 值)的贡献不同, 据此可以划 分湖底类型. 依据先验知识，把太湖水生植被划分为两种类型：(1)以沉水植被主导的水生植被类; 和(2)以 浮叶植被为主导的水生植被类(包括浮叶植物、挺水植物和漂浮植物); 假设这两种类型的水生植被在空间上 不相互重叠, 同时假设三类地物(水体、以沉水植被主导的水生植被类、以浮叶植被为主导的水生植被类) 的 DN 值都满足正态分布. 首先使用实测透明度及其对应的遥感图像 DN 值，建立二者之间的经验模型，逐 像元估算透明度. 每类地物选取一定数量的典型样 点，记录并分析这些样点的 DN 值和透明度，确立分 类阈值，建立两种分类决策树模型: (1)水体透明度辅 助下的影像地物视光谱特征分类决策树模型, (2)仅 基于影像地物光谱特征的分类决策树模型; 然后对 相应的遥感影像进行分类, 最后进行精度评价.

\section{1 估算透明度}

有研究表明 ${ }^{[14-18]}$, 利用 TM 1-3 波段, 可以较 高精度地反演水体透明度. 首先将实地观测的采样 点导人 GIS 软件, 生成点图层, 然后与遥感图像进 行叠加, 记录每个采样点对应的像元值, 最后对透 明度和波段 DN 值进行多种回归分析，比较后得到 最适合的透明度估算模型:

$S D D=142.50+2.38 T M 1-3.37 T M 2-0.55 T M 3$

$\left(R^{2}=0.77, R M S E=8.24, N=15\right)$

式中, $S D D$ 为透明度 $(\mathrm{cm}), T M 1 、 T M 2$ 和 $T M 3$ 分别表 示为 $\mathrm{TM}$ 卫星遥感影像第 $1 、 2 、 3$ 波段的像元 $\mathrm{DN}$ 值, $R M S E$ 为均方根误差 $(\mathrm{cm}), N$ 为样本数. (1)式的平 均相对误差约为 $12 \%$. 把(1)式应用于太湖 TM 卫星 遥感影像, 得到整个太湖的透明度分布(图 2).

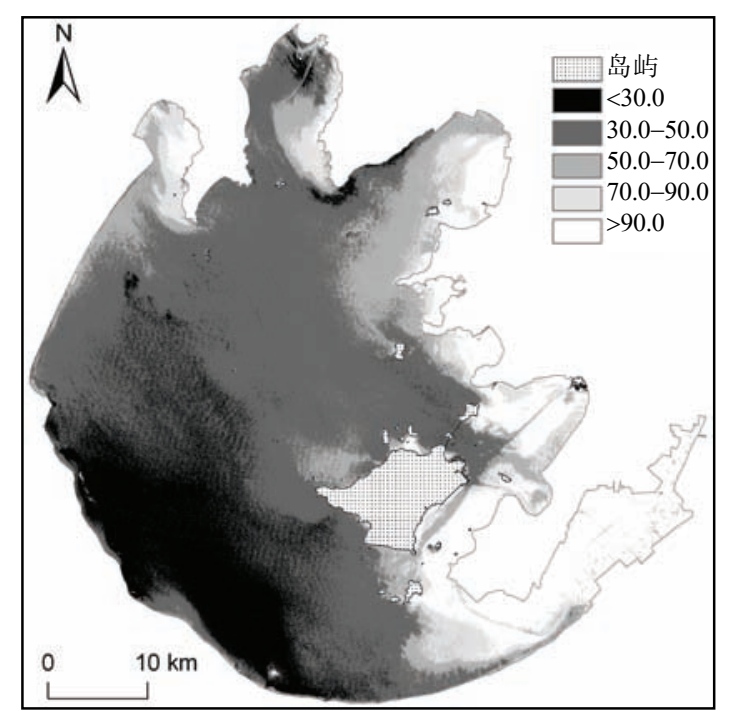

图 22002 年 7 月 15 日太湖透明度的空间分布 Fig.2 Retrieval transparency using Landsat TM image acquired on 15 July 2002 


\section{2 建立分类决策树}

2.2.1 分类波段的选择 TM 图像各波段水体像元的统计分析表明(表 1), 前三个波段(TM1、TM2、TM3) 相关性较高, 标准差均相差不大, 相关系数均在 0.9 以上, TM5 和 TM7 的相关系数也在 0.9 以上. 依据信 息最大化和地物易分性原则，最终选择 TM 3、4、5 波段用于三类地物的提取.

表 $1 \mathrm{TM}$ 太湖水体像元各波段标准差和波段间相关系数

Tab.1 Standard deviation and correlation coefficient between TM band 1-5, 7 in Lake Taihu water image pixels

\begin{tabular}{cllllll}
\hline 相关系数 & TM 1 & TM 2 & TM 3 & TM 4 & TM 5 & TM 7 \\
\hline TM 1 & 1.000 & 0.968 & 0.912 & -0.597 & -0.443 & -0.240 \\
TM 2 & 0.968 & 1.000 & 0.945 & -0.509 & -0.354 & -0.156 \\
TM 3 & 0.912 & 0.945 & 1.000 & -0.343 & -0.121 & 0.113 \\
TM 4 & -0.597 & -0.509 & -0.343 & 1.000 & 0.918 & 0.745 \\
TM 5 & -0.443 & -0.354 & -0.121 & 0.918 & 1.000 & 0.938 \\
TM 7 & -0.240 & -0.156 & 0.113 & 0.745 & 0.938 & 1.000 \\
各波段标准差 & 10.747 & 11.483 & 11.394 & 3.188 & 3.792 & 3.172 \\
\hline
\end{tabular}

2.2.2 类别阈值的确定 考虑因植被类型和覆盖度以及水深等因素引起的地物类型内部差异，在保证样点 DN 值间方差最大的情况下, 每类地物选取 1000 个代表性的样点, 记录这些样点的 DN 值, 在 TM3、4、5 之间进行不同波段的组合运算，统计每类地物在这些波段或者波段组合上的最大和最小值. 如果某个波段 或者波段组合上每类地物间最大和最小值没有重叠区间或者重叠区间很小，则这个波段组合适合用于分类. 使用 TM3 和 TM4, 分别计算太湖三种地物类型(水体、以沉水植被主导的水生植被类和以浮叶植被为主 导的水生植被类)的植被指数 RVI(NIR/Red $)$ 和 $\operatorname{NDVI}((N I R-R e d) /(N I R+R e d)$ (表 2，表 3); 结果表明，它们的 RVI 和 NDVI 没有重叠区间, 为了避免像元漏分, 分别取地物间最大值和最小值的平均值为决策树阈值.

表 2 三种地物类型在 RVI 上的统计结果

Tab.2 The statistical results of the three types on RVI image

\begin{tabular}{cccccc}
\hline 类型 & 最小值 & 最大值 & 均值 & 标准差 & 最大最小值内样点数占总样点数的比例 $(\%)$ \\
\hline 水体 & 0.247 & 0.306 & 0.280 & 0.016 & 95.17 \\
沉水植被 & 0.337 & 0.435 & 0.388 & 0.025 & 95.95 \\
浮叶植被 & 0.522 & 1.285 & 0.827 & 0.202 & 95.90 \\
\hline
\end{tabular}

表 3 三种地物类型在 NDVI 上统计结果

Tab.3 The statistical results of the three types on NDVI image

\begin{tabular}{cccccc}
\hline 类型 & 最小值 & 最大值 & 均值 & 标准差 & 最大最小值内样点数占总样点数的比例 $(\%)$ \\
\hline 水体 & -0.600 & -0.507 & -0.564 & 0.019 & 96.36 \\
沉水植被 & -0.488 & -0.387 & -0.442 & 0.025 & 95.77 \\
浮叶植被 & -0.287 & 0.280 & -0.107 & 0.116 & 95.53 \\
\hline
\end{tabular}

2.2.3 建立决策树 假设当水体透明度小于 $Z$ 时, 无水生植被生长, 其中有浮叶植被分布的水域最小透明度 为 $H_{f}$, 有沉水植被分布的水域最小透明度为 $H_{s}$. 根据陈洪达和任久长等 ${ }^{[19-20]}$ 研究结果以及太湖水深和卫星 影像成像时刻季节的实际情况, $H_{f}$ 取为 $65 \mathrm{~cm}, H_{s}$ 可取为 $70 \mathrm{~cm}$, 然后结合 RVI 和 NDVI 的类别阈值, 建立 如图 3 所示的分类决策树, 简称方法一. 为便于对比分析, 直接基于三类地物的光谱统计特征, 建立无水 体透明度参与的分类决策树(图 4), 简称方法二.

\section{3 结果分析}

方法二的分类结果表明(图 5), 两种植被指数的分类结果基本相同, 梅梁湾、竺山湾和太湖西南沿岸 
沉水植被和浮叶植被均大面积分布. 而卫星影像获取时段内 的实地调查表明, 梅梁湾和竺山湾只有在湖岸附近有少量水 生植被分布. 相关研究也表明 ${ }^{[21]}$ ，在西部及北部湖区，水生 植被主要分布在沿湖岸线及湖中岛屿岸边约 30-500m、水深 小于 $1 \mathrm{~m}$ 水域范围内. 基于遥感图像上地物光谱特征的分类结 果与实际相差较大. 竺山湾和梅梁湾水体含有高浓度的藻类 和悬浮物质, 与 $\mathrm{TM}$ 图像水生植被的表观光谱特性相似, 形成 了“异物同谱”现象, 从而造成了不同地物的混淆, 增加了水生 植被信息的提取误差.

与方法二的分类结果相比, 方法一中梅梁湾、竺山湾和太 湖西南沿岸水生植被的空间分布与实际情况基本吻合(图 6), 其它湖区水生植物分布几乎没有变化. 从水生植被空间分布 的角度看, 方法一的分类结果好于方法二. 方法一的分类结 果表明, 太湖全湖沉水植被面积约 $489.8 \mathrm{~km}^{2}$, 其中以沉水植 被为主导的水生植被约 $407.6 \mathrm{~km}^{2}$ (表 4).

每类地物随机选择 256 个像元, 使用 ERDAS IMAGINE 对分类结果进行精度评价, 结果表明(表 5 和表 6), 方法二的 分类结果与实际情况相差较大, 特别是在悬浮物和藻类浓度 较高的水域如梅梁湾, 大量水体被误分为沉水植被和浮叶植 被; 方法一的分类结果中, 水体被误分为沉水植被的像元明 显减少, 并且能更有效的提取浮叶植被. 浮叶植被的提取误 差主要由藻类引起. TM 图像上, 聚集的藻类具有与浮叶植被 相类似的光谱特征, 单纯利用光谱特征很难将其和浮叶植被 区分开; 沉水植被的误差主要由水体中的悬浮物引起, 在悬 浮物浓度较高的水域如西南沿岸和竺山湾等, 方法二把大面 积水体分为沉水植被. 另外, 两种分类方法中, NDVI 和 RVI 的对比分析表明, 使用 NDVI 的分类方法总体精度平均提高 了 $8.5 \%$, Kappa 系数提高了 0.11 , 表明 NDVI 的分类方法好于

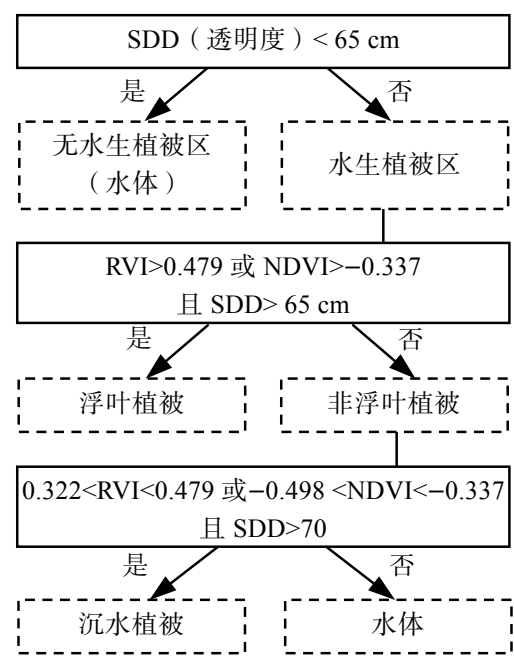

图 3 透明度参与辅助分类的决策树 Fig.3 The decision tree including transparency retrieved from TM

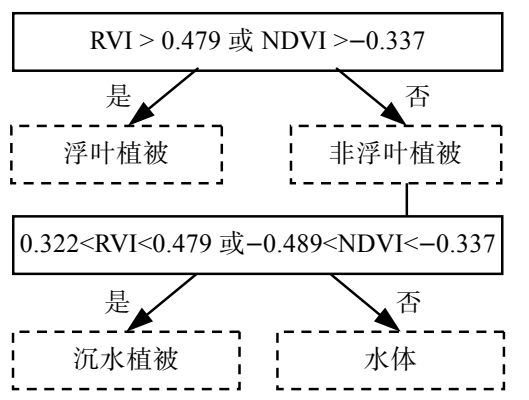

图 4 无水体透明度参与的决策树

Fig. 4 The decision tree only based on image pixel statistical feature

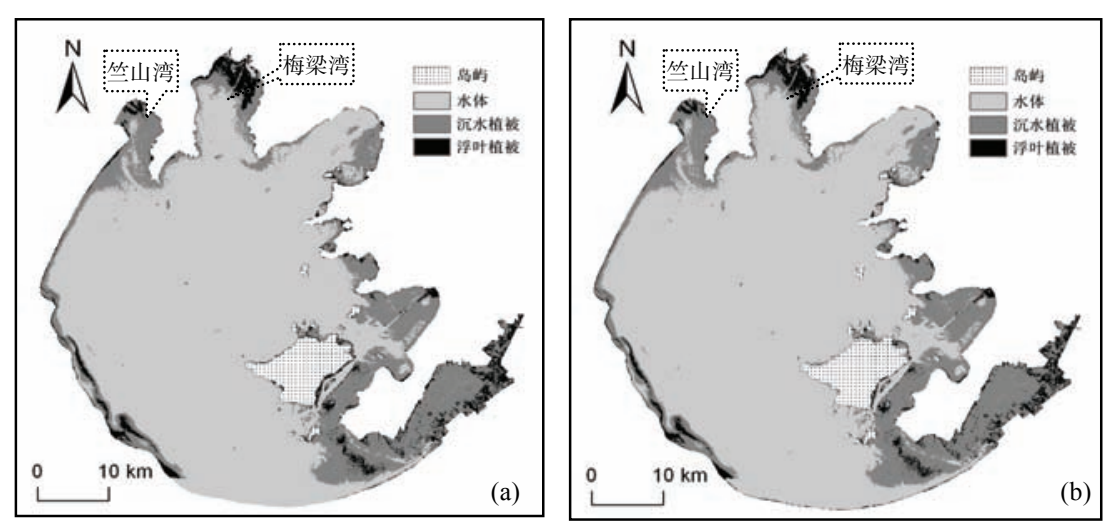

图 5 无透明度参与的太湖水生植被分类(水体、以沉水植被为主导的水生植被类、以浮叶 植被为主导的水生植被类): (a)利用 RVI 的分类结果; (b)利用 NDVI 分类结果

Fig.5 Hydrophytes classification result (including water body, submerged vegetation-dominated hydrophytes and floating vegetation-dominated hydrophytes), using the following vegetation index only based on the image pixel statistical feature: (a) RVI vegetation index; (b) NDVI vegetation index 


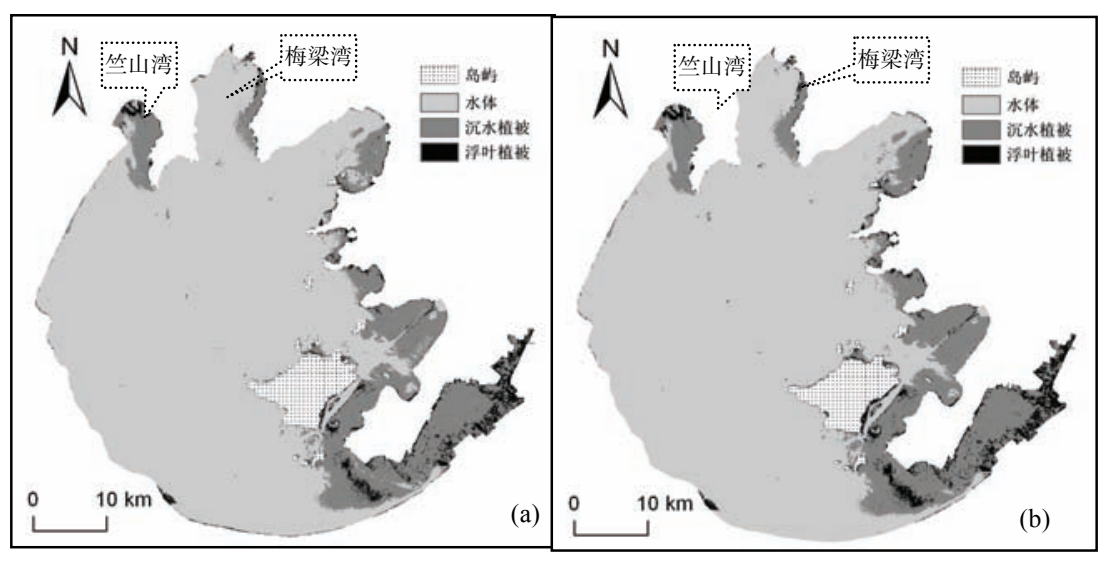

图 6 水体透明度参与的太湖水生植被分类(水体、以沉水植被为主导的水生植被类、以浮叶植 被为主导的水生植被类): (a)利用 RVI 的分类结果; (b)利用 NDVI 分类结果

Fig.6 Hydrophytes classification result (including water body, submerged vegetation-dominated hydrophytes and floating vegetation-dominated hydrophytes), using the following vegetation index only based on the transparency and the image pixel statistical feature: (a) RVI vegetation index;

(b)NDVI vegetation index

表 4 两种分类结果对比

Tab.4 Comparison between the result data from the two approaches

\begin{tabular}{lll}
\hline & $\begin{array}{l}\text { 以沉水植被为主导的 } \\
\text { 水生植被 }\left(\mathrm{km}^{2}\right)\end{array}$ & $\begin{array}{l}\text { 以浮叶植被为主导的 } \\
\text { 水生植被 }\left(\mathrm{km}^{2}\right)\end{array}$ \\
\hline 方法一(透明度参与的分类决策树) & 407.6 & 82.2 \\
方法二(无透明度参与的分类决策树) & 493.7 & 114.6 \\
\hline
\end{tabular}

表 5 基于 RVI 的分类后误差矩阵*

Tab.5 Error matrix of classification based on RVI

\begin{tabular}{lcccc}
\hline \multirow{2}{*}{ 分类结果 } & \multicolumn{3}{c}{ 实际类型 } & \multirow{2}{*}{ 总计 } \\
\cline { 2 - 5 } & 水体 & 沉水植被 & 浮叶植被 & \\
\hline 水体 & 254 & 2 & 0 & 256 \\
沉水植被 & 82 & 174 & 0 & 256 \\
浮叶植被 & 91 & 8 & 157 & 256 \\
总计 & 427 & 184 & 157 & 768 \\
\hline
\end{tabular}

*总分类精度 $=76.2 \%, \mathrm{Kappa}=0.643$.
表 6 基于 RVI 和透明度数据的分类后误差矩阵 ${ }^{*}$ Tab.6 Error matrix of classification based on RVI and water transparency

\begin{tabular}{llcccc}
\hline \multirow{2}{*}{ 分类结果 } & \multicolumn{4}{c}{ 实际类型 } & \multirow{2}{*}{ 总计 } \\
\cline { 2 - 5 } & 水体 & 沉水植被 & 浮叶植被 & \\
\hline 水体 & 253 & 3 & 0 & 256 \\
沉水植被 & 37 & 214 & 5 & 256 \\
浮叶植被 & 43 & 2 & 211 & 256 \\
总计 & 333 & 219 & 216 & 768 \\
\hline
\end{tabular}

*总分类精度 $=88.3 \%$, Kappa $=0.824$.

RVI. 透明度作为决策树的一个变量, 其反演精度直接影响着水生植被空间分布的提取结果. 东太湖面积 约 $131 \mathrm{~km}^{2}$, 悬浮物和藻类浓度低, 透明度高, 在水生植被提取时几乎不存在“异物同谱”现象, 两种方法 提取的水生植被面积几乎没有变化, 分别为 $125.3 \mathrm{~km}^{2}$ 和 $125.8 \mathrm{~km}^{2}$. 因此在不受“异物同谱”现象干扰的水 域，是否有透明度参与的分类方法几乎不会影响水生植被的提取精度. 方法一和方法二的分类结果中， 沉水植被和浮叶植被的面积分别减少 $17.5 \%$ 和 $28.3 \%$ (表 4), 认为是透明度参与下“异物同谱”现象被克服 的表现. 


\section{4 结论与讨论}

水生植物作为湖泊生态系统中的初级生产者, 具有显著的环境生态功能, 此外, 水生植被对湖泊水 体的物理和化学环境有显著的改善作用 ${ }^{[22-23]}$. 太湖受人类活动影响特别大, 水生植物空间分布变化快. 传统的水生植物调查方法费时费力, 制图周期长, 不能快速、大尺度地监测水生植物的变化. 遥感目前已 经成为获取地表信息的主要来源, 遥感技术监测湖泊水生植被变化成为有效手段, 特别是大型湖泊. 通 过 TM 图像反演水体的透明度, 通过地物样点的统计确定分类阈值, 然后用透明度数据辅助 RVI 和 NDVI, 实现水生植被空间分布信息的提取, 结果表明特别是在藻类较大面积集聚和悬浮物浓度较高的水域, 透 明度辅助下的决策树分类可以显著提高水生植被的分类精度. 在悬浮物浓度较高的水域, 水体在 TM 图 像上具有和沉水植被相类似的光谱特征; 在藻类浓度较高的水域, 水体在 TM 图像上具有和浮叶植被相 类似的光谱特征，从而造成了水生植被分类时的 “异物同谱” 现象，降低了水生植被的分类精度. 值得注 意的是, 在藻类和悬浮物浓度较高的水域, 透明度很低; 使用透明度辅助的决策树分类方法, 可以增加 水体与水生植被的可分性，总分类精度提高了约 $12 \%$; 另外，透明度辅助下的 NDVI方法好于透明度辅助 下的 RVI 方法, 透明度辅助下的 NDVI 方法的总分类精度提高了约 $8.5 \%$. 因此, 透明度辅助下的 NDVI 分类决策树方法是进行太湖水生植被分类的一种最好方法选择，把这种方法应用于 2002 年 7 月 15 日的 Landsat ETM 卫星遥感影像, 结果表明太湖中以沉水植被为主导的水生植被约 $407.6 \mathrm{~km}^{2}$, 以浮叶植被为 主导的水生植被约 $82.2 \mathrm{~km}^{2}$.

本文把太湖水生植被分为以浮叶植被为主导的水生植被类和以沉水植被为主导的水生植被类, 仅是 从水生植被生物量遥感估算的角度提出的分类方法, 目的是为了提高生物量的估算精度. 仅从水生植被 物种的角度, 使用卫星遥感的方法还存在一定的困难：(1)同一样点的水生植被往往包含多种, 以群丛的 方式出现, 因此该样点实测的或卫星遥感影像表现出的光谱特征/特性是本样点所有水生植被光谱特征/ 特性的综合; (2)高光谱或超光谱遥感可以区分不同种类的水生植被，技术上、方法上是可行的，但高光谱 或超光谱卫星遥感影像的获取较为困难, 目前唯一一颗星载在轨的高光谱卫星传感器 EO-1 Hyperion 的 遥感影像需要编程订购, 景幅较窄 (仅 $7 \mathrm{~km}$ ), 覆盖整个太湖至少需要 10 景, 并处于不同的轨道, 获取的时 间各不相同. 多光谱卫星遥感影像(如 Landsat TM/ETM)的光谱分辨率较低, 尚不能区分不同的植被物种.

\section{5 参考文献}

[1] Zhang Yunlin, Qin Boqiang, Chen Weimin et al. Attenuation of hotosynthetically Available Radiation (PAR) in Meiliang Bay under different winds and waves. Chinese Journal of Applied Ecology, 2005, 16(6): 1133-1137.

[2] Zhang Yunlin, Qin Boqiang, Chen Weimin et al. Experimental study on underwater light intensity and primary productivity caused by variation of total suspended matter. Advances in Water Science, 2004, 15(5): 615-620.

[3] Jollineau M, Howarth P. Use of high-resolution imagery to map wetland environments in South-enteral Ontario, Canada. Geoscience and Remote Sensing Symposium, 2002, 5: 3089-3091.

[4] Wolter P, Johnston CA, Niemi GJ. Mapping submergent aquatic vegetation in the US Great Lakes using Quickbird Satellite Data. International Journal of Remote Sensing, 2005, 26: 5255-5274.

[5] Using satellite remote sensing to map aqatic vegetation. http://rsl.gis.umn.edu, 2007-9-5.

[6] Jakubauskas ME, Dana L, Peterson et al. Mapping and Monitoring Invasive Aquatic Plant Obstructions in Navigable Waterways Using Satellite Multispectral Imagery. http://www.isprs.org, 2007-9-5.

[7] 李仁东, 刘纪远. 应用 Landsat ETM 数据估算鄱阳湖湿生植被生物量. 地理学报, 2001, 56(5): 532-540.

[8] 邬国锋, 刘耀林, 纪伟涛. 利用 Landsat $5 \mathrm{TM}$ 影像估算沉水植物地上生物量的研究——以江西省鄱阳湖国家自然保护区 为例. 武汉大学学报(信息科学版), 2006, 31(11): 953-957.

[9] 简永兴, 李仁东, 王建波等. 鄱阳湖滩地水生植物多样性调查及滩地植被的遥感研究. 植物生态学报, 2001, 25(5): 581-587.

[10] Stewart CC, Freedman B. Comparison of the macrophyte communities of a clearwater and a brownwater Oligotrophic Lake in 
Kejimkujik National Park, Nova Scotia. Water Air and Soil Pollution, 1989, 46: 335-341.

[11] Squires MM, Lesack LFW, Huebert D. The influence of water transparency on the distribution and abundance of macrophytes among lakes of the Mackenzie Delta, Western Canadian Arctic. Freshwater Biology, 2002, 47(11): 2123-2135.

[12] Eklund PW, Kirkby SD, Salim A. Data mining and soil salinity analysis. International Journal of Geographical Information Science, 1998, 12(3): 247-268.

[13] Ma Ronghua, Tang Junwu, Dai Jinfang. Bio-optical model with optimal parameter suitable for Lake Taihu in water colour remote sensing. International Journal of Remote Sensing, 2006, 27: 4303-4326.

[14] Lathrop RG, Lillesand TM. Use of Thematic Mapper Data to assess water quality in Green Bay and Central Lake Michigan. Photogrammetric Engineering and Remote Sensing, 1986, 52(5): 671-680.

[15] Kloiber SM, Brezonik PL, Bauer ME. Application of landsat imagery to regional-scale assessments of lake clarity. Water Research, 2002, 36(17): 4330-4340.

[16] Kloiber SM, Brezonik PL, Olmanson LG et al. A procedure for regional lake water clarity assessment using Landsat Multispectral Data. Remote Sensing of Environment, 2002, 82(1): 38-47.

[17] 王得玉, 冯学智. 基于 TM 影像的钱塘江人海口水体透明度的时空变化分析. 江西师范大学学报(自然科学版), 2005, 29(2): 185-189.

[18] 邬国锋, 刘耀林, 纪伟涛. 基于 TM 影像的水体透明度反演模型一以鄱阳湖国家自然保护区为例. 湖泊科学, 2007, 19(3): 235-240.

[19] 陈洪达. 武汉东湖水下光照强度对水生植物的影响. 湖北渔业, 1990, 2: 20-24

[20] 任久长, 周 红, 孙亦丹. 滇池光照强度的垂直分布于沉水植物的光补偿深度. 北京大学学报(自然科学版), 1997, 35(2): 211-214.

[21] 秦伯强, 胡维平, 陈伟民等. 太湖水环境演化过程与机理. 北京: 科学出版社, 2004: 290 .

[22] 刘伟龙. 太湖水生植物时空变化特征及优势种马来眼子菜的生态响应[博士学位论文]. 北京：中国科学院研究生院, 2007.

[23] 种云霄, 胡洪营, 钱 易. 大型水生植物在水污染治理中的应用研究进展. 环境污染治理技术与设备, 2003, 4(2): 36-40. 